\title{
A institucionalização do mercado noticioso e seus significados para a construção da identidade do jornalista no Brasil
}

Fernanda Lima Lopes

\section{Resumo}

A consolidação da atividade jornalística como uma profissão e o reconhecimento dos jornalistas derivam, em grande parte, de processos de valorização mercantil da informação, os quais não podem ser vistos sem se prestar atenção à formação e ao crescimento das empresas jornalísticas e corporações de mídia. Este artigo justifica a importância de se focalizar a instituição ou empresa a fim de relacionar transformações midiáticas e o desenvolvimento/profissionalização do jornalismo no Brasil. Nessa perspectiva, analisa a construção da identidade do jornalista em momentos-chave do decorrer da história da imprensa no país e inclui reflexões sobre o momento contemporâneo, quando internet e novas tecnologias estabelecem novas práticas, rotinas, condições de acesso à produção, circulação e consumo de conteúdos informativos, o que representa reconfigurações no jornalismo.

Palauras-chave:

Jornalismo, Identidade Jornalística, Âmbito Institucional

\section{The institucionalization of the news market and its meanings for identity construction of Brazilian journalist}

\section{Abstract}

Sobre a autora

Doutoranda em Comunicação e Cultura pela UFRJ, Mestre em Comunicação e Cultura pela UFRJ e graduada em Comunicação Social/Jornalismo pela UFMG ferdynanda@yahoo.com
The growing recognition of journalism as a profession cannot be understood without regarding the formation and development of news corporations. Therefore, we analyse the identity construction of journalists in key points of the press history in Brazil and reflect over the contemporary moment, when the Internet and new technologies set new practical routines, conditions of access to media production, circulation and consuming patterns of news content. Changes that represent new configurations in journalism.

Keywords:

Journalism, Journalistic Identity, Institutional level 
Médicos, dentistas, advogados e outros cujas atividades apresentam certa liberdade de exercício da função não são encarados como empregados (ainda quando são funcionários de empresas), mas sim como profissionais liberais. Não raro essa mesma classificação é atrelada aos jornalistas, fato que Joaquim Fidalgo (2009) considera pertinente até um certo limite. $\mathrm{O}$ autor esclarece que a imagem de profissão liberal é tributária de um senso socialmente partilhado acerca da autonomia atribuída a esses atores no desempenho de seu trabalho e, de fato, o agir profissional dos jornalistas deixa transparecer traços de um fazer autônomo, na medida em que se caracteriza por um viés marcadamente intelectual e se aproxima de formas de expressão que podem ser incrementadas por atributos como a criatividade e até mesmo uma estética artística e literária. No entanto, há uma dimensão do trabalho desses profissionais que destoa do sentido geral de profissão liberal, uma vez que jornalistas são trabalhadores assalariados prestando serviço dentro de uma empresa jornalística (KUNCIZK, 2002; FIDALGO, 2009).

É óbvio que não se pode reduzir o grupo dos jornalistas exclusivamente aos funcionários das empresas de comunicação. Sobretudo no contexto contemporâneo, em que as novas tecnologias, com suas novas formas de produção, circulação e consumo da informação impactam de maneira decisiva a questão de alguns monopólios e especificidades até então extremamente atrelados aos poderes e controles das organizações empresariais.

De qualquer maneira, ainda que se possa considerar que a internet efetiva algum grau de democratização da informação e que isso representa pontos de tensão e motivo de reorganizações para o jornalismo na contemporaneidade, não se pode esquecer o peso fulcral das corporações de mídia para a definição de elementos significativos para a construção da identidade do jornalista, principalmente (mas não apenas) no âmbito de suas práticas. Nesse sentido, este trabalho busca abordar os seguintes tópicos no decorrer da discussão que se propõe a fazer:

1 - apresentar, com mais cuidado e aprofundamento, as justificativas teóricas e epistemológicas para que se enxergue o âmbito institucional - sobretudo a empresa jornalística - como instância importantíssima para a construção da identidade do grupo profissional em questão.

2 - Mantendo o foco sobre a instituição ou empresa, estabelecer relações entre transformações midiáticas e o desenvolvimento/profissionalização da atividade jornalística no Brasil. Isso será feito pela análise de alguns momentos-chave do decorrer da história da imprensa no país, a partir dos quais se busca perceber nessa relação de que maneira aquilo que ocorreu e ocorre institucionalmente afetou e continua a afetar a identidade dos jornalistas brasileiros.
Não se pode reduzir o grupo dos jornalistas exclusivamente aos funcionários

das empresas

de comunicação. Sobretudo no contexto contemporâneo 
3 - Ainda tendo em vista a perspectiva da empresa jornalística, mas sem excluir novas formas institucionais para o exercício da atividade jornalística, direcionar a reflexão sobre a construção da identidade do jornalista para o momento contemporâneo, em que reconfigurações no jornalismo são notadas em virtude da internet e das novas tecnologias, as quais estabelecem novas práticas, rotinas, condições de acesso à produção, circulação e consumo de conteúdos informativos.

Antes de iniciar o caminho proposto, vale lembrar que é exatamente disto que se trata: um caminho proposto. As limitações de espaço permitidas por um artigo apontam para a óbvia necessidade de se promover um recorte. Neste caso, a opção é pelo universo das empresas jornalísticas, mas não que isso signifique a negligência de outras dimensões também fundamentais para a construção da identidade do jornalista, as quais poderão ser contempladas em outros trabalhos.

Há que se esclarecer também que o recorte que privilegia essa dimensão não é apenas uma secção arbitrária efetuada pelo imperativo das limitações espaciais. Mais do que isso, tem razões epistemológicas para que se possam realizar reflexões profícuas a partir dessa perspectiva, tal como veremos a seguir.

\section{Justificando a abordagem}

Enric Saperas (2000) aponta que a sociofenomenologia (ou sociologia fenomenológica) de autores como Alfred Schutz, Berger e Luckmann foi um contributo teórico importante para embasar trabalhos de pesquisadores como a socióloga americana Gaye Tuchman e o italiano Giogio Grossi sobre jornalismo, principalmente os que se propunham a investigar a construção social da realidade operada pelas notícias.

$\mathrm{Na}$ opinião de Saperas (2000), esses autores que tratavam de temas ligados à comunicação aperfeiçoaram as bases epistemológicas provenientes do campo da sociologia fenomenológica, uma vez que superaram alguns direcionamentos demasiadamente individuais presentes na obra de Schultz, por exemplo. Tuchman e Grossi fazem esse salto ao reconhecer que, a fim de conceber o caráter construtivista da atividade humana, além dos aspectos relativos à subjetividade e intersubjetividade, era imprescindível levar em conta as formas objetivadas implicadas na construção da realidade. Assim, ao considerarem os aspectos objetivos do processo de construção da notícia, incluíam entre estes as instituições implicadas nas práticas de seleção e narração do conteúdo informativo. "A informação e os profissionais da comunicação colectiva serão o detonante que impulsionou esta renovação teórica" (SAPERAS, 2000: 139).

Trabalhos de Tuchman e Grossi estão entre os que se esforçam para demonstrar que as notícias não são um mero reflexo da realidade, como um espelho, mas sim produto de relações complexas, as quais incluem os processos institucionalmente sedimentados.

${ }^{1}$ Essa foi a lógica, de acordo com Costa (2009), para o desenvolvimento dos jornais de Adolph Ochs, nos Estados Unidos, no final do Oitocentos. A passagem da gazeta de opiniões para o jornal de notícias fundamentou-se no preceito de que "quanto menos pudesse tomar partido em alguma notícia, quanto mais 'independente' se mostrasse, mais valor teria a notícia, porque interessaria aos vários lados, interessaria todos" (idem, ibidem, p. 156). 
Nesse sentido, práticas, rotinas, pressões, relações de poder e hierarquias dentro dos locais de trabalho necessariamente afetam a escolha dos fatos que serão notícia, o modo de narrá-los e outras formas de apresentação estampadas no produto que chega ao consumidor de informação jornalística.

As pesquisas dessa vertente ajudam a compreender que os modos como produtos jornalísticos (nomeadamente: as notícias) constroem a realidade social não são resultado de um automatismo refletivo do discurso ou das escolhas pessoais e subjetivas de quem produz esse discurso, mas estão sujeitos a condições objetivas das instâncias institucionais.

Conforme Saperas:

um dos principais contributos da aproximação sociofenomenológica para o estudo dos efeitos cognitivos da comunicação de massa foi a análise da profissão jornalística como resultado da actividade de um tipo de actor social cuja acção (conducente à construção da realidade social) se encontra institucionalizada e socialmente reconhecida nas suas competências. (SAPERAS, 2000: 143)

Essa valorização do âmbito institucional para a compreensão do jornalismo também marca trabalhos brasileiros, como o de Zélia Adghirni, "Rotinas produtivas do jornalismo em Brasília" (2002), em que a investigação abrange uma observação das relações e práticas do jornalista com suas fontes e entre seus colegas de profissão, concorrentes ou não, mas também presta atenção às rotinas e relações sociais e trabalhistas dentro do espaço de trabalho institucional que são as redações. Tudo isso contribui para a análise que a autora faz sobre as notícias que são criadas em meio a essa complexidade de fatores.

Se por um lado os estudos de Tuchman, Grossi e outros autores preocupados com o espectro do chamado newsmaking mostram a importância do olhar sobre os bastidores da produção da notícia como forma de compreender o processo de construção da realidade social efetuado pelos produtos jornalísticos informativos, esses mesmos bastidores podem ser investigados para procurarmos pistas sobre as práticas, rotinas, relações de poder, normas, saberes, valores e outros aspectos que contribuem para a constituição de parâmetros e referências que servem à identificação do jornalista. Assim se passa com os produtos, bem como com os agentes. Isso é o que este trabalho procura sustentar.

Dessa maneira, pode-se afirmar que jornalistas inseridos em determinadas lógicas de funcionamento das empresas acabam por adquirir, desenvolver, partilhar modos pelos quais eles se apresentam para a sociedade e também a forma como a sociedade os enxerga através de alguns mecanismos operados pelas
Bastidores da produção da notícia como forma de compreender

- processo de construção da realidade social efetuado pelos produtos jornalísticos informativos, esses mesmos bastidores podem ser investigados para procurarmos pistas sobre as práticas, rotinas, relações de poder, normas, saberes, valores e outros aspectos que servem à identificação do jornalista 
instituições. É, portanto, da produção de uma certa imagem que

A consolidação da atividade se trata aqui. Imagem que é fruto das marcas das ações que executam dentro da empresa ou na qualidade de funcionários dessas empresas, e tornadas visíveis pelos dispositivos de visibilidade sob a égide dessas organizações. Em outras palavras: as lógicas das organizações e de seus dispositivos imprimem uma certa imagem ao jornalista (impressão sempre mesclada com outras tintas, vale lembrar) e a tornam visível ao público.

Mas é imprescindível esclarecer que, ao mesmo tempo, essa imagem também é impressa pelo modo como esse grupo profissional atua sobre as organizações e os meios, com valores, práticas e estilos não necessariamente vinculados à lógica da corporação. Eles trazem bagagem de suas lutas sindicais, da formação universitária, enfim, são formados por outras referências que não deixam de existir quando o jornalista desempenha suas tarefas no dia-a-dia de seu local de trabalho na empresa jornalística.

Ao tratar do jornalista com vistas a investigar sua identidade profissional, é de suma importância prestar atenção a como ele age, como é seu trabalho. A importância dessa abordagem já foi até aqui justificada por referências teóricas presentes em trabalhos que também postulam a influência das formas institucionais nos fazeres e resultados desses fazeres. Elas mostram o quanto é relevante observar a complexidade dos fenômenos subjetivos e objetivos do trabalho, das práticas, das rotinas, das escolhas dos agentes, das condições em que essas escolhas são feitas, dos constrangimentos organizacionais...

$\mathrm{E}$ ao reafirmar isso, vale também trazer novamente à tona a advertência de que o privilégio sobre a empresa jornalística não significa ignorar outros âmbitos não empresariais desses atores. Acontece que a consolidação da atividade jornalística como uma profissão, bem como o seu reconhecimento na sociedade, o alcance do seu prestígio e a força do discurso do jornalismo frente a outros atores sociais (como os políticos, os artistas, os jogadores de futebol, por exemplo) são, em grande parte, devidos a processos de valorização inclusive mercantil da informação, os quais não podem ser vistos sem se prestar atenção à formação e crescimento das empresas jornalísticas e corporações de mídia. E talvez esta última razão apresentada, tão direta e simples quase simplória, para leitores mais exigentes - seja a justificativa de maior peso para a abordagem proposta.

\section{Jornalismo e empresas no Brasil ao longo do tempo}

Um ponto marcante para transformações institucionais no jornalismo é a incorporação na imprensa de uma concepção de notícia como mercadoria. É claro que esse "ponto" não pode ser tomado como uma marcação específica, afinal, essa mencionada concepção não é algo que aparece em um lugar ou num tempo exatos, mas sim um entendimento teoricamente trazido à tona a 
partir da percepção de que a lógica de mercado não é o que embala e alimenta prioritariamente a imprensa em seu nascedouro, mas é aquilo que vai nitidamente se incorporando a ela na medida de seu crescimento e desenvolvimento, de modo a tornar-se inseparável.

Variados autores que tratam da história da imprensa no Brasil (SODRÉ, 1977; ABREU, 2002; RIBEIRO, 2000; BARBOSA, 2007), ao apontar para os primórdios dessa atividade no país, mostram uso social dos jornais como plataforma para propagação expressamente ideológica. Sem muito esforço, os periódicos podiam ser classificados em segmentações do tipo republicanos, monarquistas, abolicionistas... É a chamada imprensa panfletária. Conforme tal lógica de funcionamento, o caráter institucional desses periódicos aproxima-se muito mais do modelo de organizações comprometidas com a veiculação de ideias do que com instituições do tipo mercantil que exploram o seu conteúdo simbólico como fonte direta ou indireta de lucratividade para a empresa.

Mas não demorou para que o viés empresarial e mercadológico aparecesse na atividade da imprensa e representasse impactos profundos sobre ela. Michael Schudson relata que a imprensa nos Estados Unidos sofreu, nos anos 1830, o que ele chama de "revolução comercial" (1978: 17), quando as receitas para sustentar o periódico deixaram de vir prioritariamente da venda de exemplares e passaram a derivar da publicidade. Nesse contexto, alguns jornais, a fim de alcançarem alta circulação e dessa forma serem mais vantajosos para os anunciantes, passam a adotar a filosofia de venda a preço baixíssimo, fenômeno que ficou conhecido como "penny press".

Schudson acrescenta que nesse intuito de aumentar o número de anunciantes e leitores, além de quebrarem a barreira do preço alto, os jornais procuraram vencer a barreira da vinculação estrita com a política. Assim, tinham um discurso sobre a igualdade de todo anunciante, bem como buscavam deixar claro aos consumidores que não estavam subservientes a ninguém em particular. Segundo Schudson (1978), essas, entre outras mudanças desde o século XIX, encontram-se na raiz do surgimento do ideal da objetividade, traço significativo para o jornalismo até hoje.

No caso do Brasil, a década de 1950 é o momento chave para marcar a transformação definitiva de um modelo panfletário e partidário das publicações para o modelo do jornalismo objetivo, perfeitamente congruente com a lógica empresarial de fabricação da notícia e de outros produtos jornalísticos que também ajudam a vender jornal. É preciso destacar, contudo, tal como fazem Barbosa (2007) e Ribeiro (2000), que alguns importantes deslocamentos nesse sentido não são exclusividade da década de 1950, mas remetem a desde o início do século XX.
No Brasil, a década de 1950 é

o momento chave para marcar a transformação defínitiva de um modelo panfletário

e partidário para

o modelo do jornalismo objetivo 
Barbosa (2007) relata que na virada do século XIX para o XX, a efervescência do progresso e da modernização chegava à sociedade brasileira, inclusive na imprensa. Telégrafo e impressoras rotativas eram o signo da velocidade e da chegada do futuro! A autora descreve a formação dos conglomerados de imprensa no final dos anos 1920 e anos 30, metonimicamente representados pela figura do famoso político e dono de meios de comunicação Assis Chateaubriand.

Também Ribeiro (2000), cujo trabalho minucioso procura explicar as transformações na imprensa na década de 1950, remonta à industrialização dos processos de impressão do início do século, embora deixe claro que não foi isso que transformou a relação de jornais e jornalistas com o modo de se fazer notícia, ainda extremamente modulado pelos interesses políticos. Explica a autora que a interação com a política e a presença desses interesses continuarão existindo na relação com a imprensa, todavia com a profissionalização e autonomização do jornalismo, outros fatores servirão para modulá-lo e modelá-lo.

Sob esses aspectos, já não se pode questionar o caráter dos signos jornalísticos como mercadorias. O termo "produto jornalístico" mostra-se adequado não só pelo fato de a notícia ser produto (com o perdão da repetição) de fabricação discursiva de enquadramento e emolduramento ${ }^{1}$ da informação que resultam numa construção da realidade social, mas porque, justamente, todos esses processos se dão no contexto de uma organização movida pela lógica mercadológica.

Para melhor compreender a relação da instituição jornalística com a identidade do jornalista, é preciso muito mais do que considerar a mercantilização da notícia e a consolidação da lógica industrial na imprensa: urge relacioná-las a outros fatores que contribuíram para que o jornalista fosse tomado como um profissional da empresa jornalística. Isso porque antes da década de 1950, o jornalismo não era exatamente concebido como profissão; muitas pessoas faziam do jornalismo um "trampolim" para a política ou um "bico". Falta de uma formação superior específica, frouxa representação sindical da categoria, baixos salários, exercício do trabalho jornalístico conjuntamente com outro emprego são alguns fatores que ilustram um fraco senso de profissionalismo e fronteiras nebulosas para a identidade de um grupo ainda pouco coeso.

Quando esses cenários começam a mudar², principalmente (mas não só) na década de 1950, cada vez mais a imagem do jornalista se distancia das figuras do literato, escritor, político, bacharel de direito para se configurar com a de um funcionário de uma empresa jornalística. Não que essas imagens tenham se descolado totalmente da sua identidade, mas foram se turvando e ficando entre os espectros daquilo que emergiu como a imagem do jornalista profissional.

Termos emprestados de Maurice Moillaud, que trata da operação de emolduramento operada pelas notícias no processo de construção da realidade pela seleção e narrativa dos fatos. Cf. Moillaud (2002)

${ }^{2}$ Para o fortalecimento da categoria, cita-se a regulamentação da profissão no governo de Getúlio Vargas, em 1938, bem como os benefícios concedidos a eles que vieram a ser dados posteriormente, como a isenção fiscal, a entrada gratuita em teatros e cinemas. No quesito formação, o primeiro curso superior de Jornalismo é de 1947, em São Paulo, e a obrigatoriedade do diploma para o exercício profissional é de 1969. 
Postos esses aspectos de ordem mais simbólica (imagem, representações, fronteiras nebulosas...), é hora de retomar o fio argumentativo inicial que destaca a importância do âmbito institucional - e a partir dos anos 1950 inegavelmente investido da lógica de mercado - para a compreensão da identidade do jornalista.

Um dos imperativos para a ação jornalística que se consolidou dentro das corporações a partir dessa época foi o ideal da objetividade. A valorização de um certo ar "imparcial" não é exclusividade dos anos 50 (RIBEIRO, 2000), mas esse ideal foi sacralizado pelas empresas por meio dos manuais de redação e da criação do cargo de copidesque. Foi também uma empresa - o jornal Diário Carioca - que teve jornalistas seus aprendendo técnicas como o lead nos Estados Unidos.

Ora, se a inclusão de novas funções e novas especificidades para o trabalho impactou o modo de se fazer jornalismo, não é menos verdade que também marcou a maneira de eles serem reconhecidos. Não que essas transformações redacionais e editoriais tenham transformado o jornalista em um ser objetivo e neutro, mas ajudaram a compor a mítica de um profissional "isento" e preocupado com o bem comum e com o interesse público.

Nesse sentido, a obediência às mudanças encampadas pela empresa, ainda que questionadas e criticadas por diversos jornalistas (como Nelson Rodrigues, por exemplo), não resultaram, ao fim e ao cabo, numa concepção de subserviência dos jornalistas aos patrões. Pelo contrário, a imagem de "objetivos" foi administrada num sentido mais positivo para a profissão por servir para a exaltação de uma certa autonomia desses profissionais em relação a interesses particulares.

Os anos 1960 e 1970 também apresentaram transformações significativas para as instituições midiáticas e algumas delas serão destacadas a fim de se promover uma reflexão acerca da reconfiguração de rotinas e práticas institucionais e suas relações com modos de visibilidade, reconhecimento e autodefinição para a categoria dos jornalistas. Com a chegada da televisão no Brasil (década de 50) e sua popularização nas décadas seguintes, as práticas do jornalismo não ficaram inertes às lógicas e técnicas do audiovisual. Esse então novo meio tanto instituiu novas rotinas de produção e consumo do produto jornalístico quanto contribuiu para a reformulação de alguns sentidos da identidade do jornalista.

O imperativo da informação imagética exigiu novas habilidades e novas sensibilidades para o jornalista desses veículos, ao mesmo tempo em que associou à já reconhecida credibilidade do jornalista em falar da realidade uma carga de veracidade nunca antes conseguida (afinal, quem poderá duvidar daquilo que se vê?). Pode-se considerar, portanto, que a televisão serviu para reforçar a imagem do jornalista como mediador objetivo entre os fatos e o público.
Com a chegada da televisão no Brasil as práticas do jornalismo não ficaram inertes às lógicas e técnicas do audiovisual 
É importante, contudo, lembrar que a consolidação da televisão coincide com uma época de ditadura militar no país, quando a censura não permitia que grande parte dos fatos viesse a público. Nem por isso as empresas jornalísticas deixaram de veicular discursos jornalísticos. Conforme relatam Silva (2007), Barbosa (2007) e Abreu (2002), os noticiários internacional, esportivo e econômico - já que o político nem sempre era bem-vindo pelos governantes - ganharam espaço nesse período (principalmente em meados dos anos 1970, na época da prosperidade da economia brasileira que ficou conhecida como "milagre econômico"). Isso incentivou, dentro dos jornais impressos, a criação de editorias e cadernos especializados, o que significou a criação de novos cargos de chefia (editores-chefe) e a especialização de jornalistas por área.

Tanto o aparecimento do meio audiovisual quanto a especialização em editorias ilustram segmentações e heterogeneidades dentro do grupo dos jornalistas. Por outro lado, não convém esquecer um objetivo ideológico que funciona como agregador para a identidade desse grupo e que está, de certo modo, ligado ao período da ditadura no Brasil: a luta pela liberdade de expressão.

Em oposição à censura (e quase sempre ignorando a nuvem que turva a percepção da autocensura), a identidade do jornalista é, em grande medida, construída em torno do fator "liberdade de imprensa”. A ousadia dos jornais alternativos e a imagem de guardião da democracia são noções de tal forma mobilizadas pelos jornalistas que se projetam para além daqueles que foram efetivamente revolucionários. Tal ideário de luta é mobilizado e serve para gerar expectativas morais e de conduta, além de para marcar como desviantes os jornalistas subordinados ou coniventes com os silêncios da empresa jornalística comprometida com a lógica de mercado.

O escrutínio das transformações das rotinas e lógicas no âmbito das corporações jornalísticas ao longo do tempo pode continuar a ser delineado ainda sob muitos outros aspectos. De qualquer maneira, supõe-se que o esforço teórico feito, bem como os momentos analisados até aqui tenham dado conta de justificar a importância dessa abordagem e de apontar algumas marcas significativas dessa relação para a construção da identidade jornalística. Assim, mostrase adequado prosseguir para o próximo tópico que este artigo quer abordar: a investigação da identidade jornalística frente ao mercado de informações e notícias e às instituições midiáticas no contexto contemporâneo.

\section{Jornalismo no mundo contemporâneo}

Este tópico não ousa fornecer respostas completas sobre a situação vivida atualmente pelo jornalismo no Brasil, mas ainda em consonância com os objetivos gerais deste artigo, propõe apresentar cenários contemporâneos que podem significar ins-
Um objetivo

ideológico funciona como agregador para a identidade desse grupo e que está, de certo modo, ligado ao período da ditadura no Brasil: a luta pela Ifberdade de expressão 
tabilidades, reorganizações e até rupturas de algumas tradicionais formas de reconhecimento e autoridade para os jornalistas e para as empresas jornalísticas.

Tal como foi insistentemente argumentado até agora, para se pensar a relação da identidade jornalística com as instituições e lógicas de produção e consumo dos produtos noticiosos é imprescindível levar em conta a diversidade de funções, modos e locais de atuações dos membros desse grupo. Por isso, convém não esquecer uma função ocupada pelo jornalista e que nas últimas décadas tem crescido em importância no meio empresarial, no setor público e em organizações do terceiro setor. Trata-se do assessor de imprensa.

Os jornalistas têm nesses cargos uma convidativa alternativa de emprego no atual mercado de trabalho caracterizado por grande concorrência e escassez de vagas. Assim, se de um lado acompanhamos a tendência de tradicionais empresas de mídia em enxugar seus quadros funcionais, principalmente dos jornalistas com os maiores salários ${ }^{3}$, de outro lado vemos jovens e experientes profissionais do jornalismo encarando a disputa acirradíssima para as vagas de assessoria em concursos públicos.

O crescimento da importância e do prestígio da função de assessor de imprensa representa, para o grupo dos jornalistas, a existência de uma importante heterogeneidade em seu interior. E divide-os, num certo sentido, ao colocá-los em "lados opostos do balcão". A atuação desses jornalistas que prestam serviço a empresas, a órgãos do estado e da administração pública e a variados tipos de organização não está - pelo menos em tese - em conexão direta com as tradicionais esferas de produção, circulação e consumo de notícias. A ligação evidentemente existe, mas é indireta, uma vez que informações preparadas e tratadas pelo assessor de imprensa deverão passar (pelo menos supostamente) pelas peneiras dos jornalistas e empresas que serão os responsáveis pela publicação e veiculação da notícia correlacionada ao assunto tratado. (Porém, é comum um acesso direto nessa cadeia informativa, pois não raro o texto do assessor é publicado na íntegra pelo meio de comunicação que recebeu o seu release).

O trabalho jornalístico do assessor de imprensa impacta a construção da identidade jornalística no que tange à ampliação dos loci em que os sentidos para a profissão são negociados com a sociedade. Quando um jornalista faz parte do quadro de funcionários de um sindicato de professores, ou de uma associação de magistrados, ou de uma fábrica de aço, ou de uma câmara municipal, inaugura-se uma convivência daquele com os mais variados atores sociais: educadores, juízes, metalúrgicos, vereadores... Estes, por sua vez, já não conhecem a profissão de jornalista apenas através dos meios de comunicação, mas também

${ }^{3}$ Segundo Carlos Eduardo Lins da Silva (2005), em 2004 a Folha fez demissões significativas. Mas ao contrário das demissões feitas no início do projeto Folha, que promoveu reformas desse jornal na década de 1980, motivadas basicamente por "questões técnicas", os cortes do início do século XXI incidiram sobre correspondentes internacionais e outros jornalistas de grande competência e de altos salários. 
vão formando uma imagem desses profissionais a partir das representações e ações do jornalista que foi incorporado ao seu cotidiano; "o jornalista da casa", que faz as fotos dos eventos, que atualiza o site da empresa, que entrevista Fulano e Sicrano para o jornal da organização...

Outro aspecto relativo ao cenário contemporâneo e que tem impactos tantos sobre as corporações de mídia quanto sobre os processos de construção da identidade jornalística está ligado ao aparecimento e desenvolvimento das novas tecnologias de informação e comunicação, sobretudo da internet.

Num livro editado em 2002, Alzira Alves de Abreu escreve brevemente sobre alguns impactos delas para o trabalho dos jornalistas de empresa midiática:

Quanto aos jornalistas, estão se adaptando às demandas da nova tecnologia. Têm que produzir informação para um novo suporte, a tela do computador, com possibilidades de comunicação multiinterativa. (...) Os jornalistas dedicados a essa tarefa saíram recentemente das redações dos jornais tradicionais e ainda têm como modelo o formato texto. (ABREU, 2002: 56)

Àquela altura, a autora deixa claro que está ciente do caráter incipiente de seus esforços teóricos:

Ainda não é possível antecipar as conseqüências da internet na vida do cidadão e as transformações que acarretará nas formas tradicionais de mídia. O que é certo é que uma nova etapa acaba de começar. (ABREU, 2002: 57)

Passados sete anos, o livro de Joaquim Fidalgo mantém a cautela em oferecer prognósticos para a profissão de jornalista, evitando proferir qualquer sentença fatal para o grupo. Entretanto, revela um posicionamento bastante contundente ao elencar alguns aspectos que, para ele, já são suficientes para serem considerados ameaças ou indicações de que as condições do mundo contemporâneo deixam "ferido de morte o tradicional monopólio dos jornalistas no domínio da recolha, tratamento e difusão de informação noticiosa sobre a actualidade" (FIDALGO, 2009: $60)$. O professor português explica que as novas tecnologias e internet significaram não apenas uma mudança nos moldes como os jornalistas operam em seu trabalho, mas permitiram que um grande número de pessoas fossem capazes de ter acesso e operar com ferramenta que, em alguma medida, eram de uso exclusivo dos jornalistas.

A meu ver, as observações de Abreu (2002) e Fidalgo (2009) estão sobremaneira carregadas da figura do jornalista-funcionário-
Novas tecnologias e internet permitiram que um grande número de pessoas fossem capazes de ter acesso e operar com ferramenta que, em alguma medida, eram de uso exclusivo dos jornalistas 
de-empresa, ou seja, profissionais necessariamente atrelados a uma corporação que visa ao lucro. Porém, como vimos, apesar de a produção industrializada da mercadoria notícia e o local de trabalho serem balizas importantes para a definição da identidade do jornalista, este não se define exclusivamente por tais indicativos.

De fato, não é difícil reconhecer que a face mais visível e socialmente projetada desses profissionais tem sido amplamente fornecida ao longo do tempo pelos meios de comunicação social, cada um com seus poderes e autoridades também historicamente construídas (por exemplo: num primeiro momento pelos jornais impressos; nos últimos 40 anos, principalmente pela televisão). Todavia, no contexto atual, as novas tecnologias digitais e a internet abrem mais campos e possibilidades para o trabalho do jornalista ser realizado diretamente com o público, sem a mediação de uma empresa.

Entretanto, vale lembrar que o mesmo espaço que supõe uma potencial democratização da informação, do acesso, da veiculação a "todos" (porque é necessário que "todos" tenham, no mínimo, acesso a um computador com softwares, conhecimento para usá-los e acesso à web) é também ocupado pelas grandes corporações jornalísticas que já atuam nos tradicionais meios de comunicação. As grandes corporações que editam os jornais brasileiros de mais peso simbólico adentraram o universo digital, não só incluindo a versão impressa do jornal na rede, mas promovendo outras possibilidades comunicativas no site do veículo, bem como expandindo sua atuação para portais multifuncionais que também abrigam conteúdo jornalístico, como por exemplo, o grupo Folha, também administrador do Uol.com.br.

Assim, é possível perceber que as formas objetivas do âmbito institucionais não são estruturas estáticas, mas algo capaz de se reestruturar na interação com outras estruturas funcionais - no caso, as instâncias técnicas e tecnológicas presentes na realidade do mundo contemporâneo.

\section{Considerações finais}

Este artigo chega ao final trazendo a convicção de que os esforços teórico e analítico aqui desenvolvidos terão sido válidos se as justificativas apresentadas no tópico 1 , juntamente com as reflexões desenvolvidas nos tópicos 2 e 3 acerca de alguns contextos da história da imprensa, possam ter ajudado a sedimentar a compreensão de que uma investigação aprofundada sobre a identidade do jornalista prescinde de um olhar atento sobre rupturas e continuidades nos modos como o grupo constroi uma imagem de si mesmo para si e para os outros.

Compreende-se, ainda, que inúmeros contextos, saberes, fazeres, representações, valores, rotinas, pressões, hierarquizações e outros aspectos não contemplados neste artigo ainda são passí-
Novas tecnologias digitais e a internet abrem mais campos

e possibilidades para o trabalho do jornalista ser realizado diretamente com - público, sem a mediação de uma empresa 
veis de análise frente à proposta de conhecer diferentes relações que os jornalistas estabeleceram com as instituições jornalísticas e com as lógicas de produção, circulação e consumo da notícia no Brasil.

Enfim, o que é interessante evidenciar é que estudar a identidade jornalística é menos elencar um conjunto de atributos estáticos de definição para esse profissional e mais perceber como as fronteiras de tal identidade são moldadas e remoldadas tendo em vista inúmeras condições, relações e contextos vivenciados na sociedade e na cultura ao longo do tempo. Espera-se que tal compreensão, bem como os exemplos e análises contemplados pelo recorte proposto neste trabalho tenham servido para estimular outras reflexões com abordagens em outros fatores e momentos também relevantes nesse sentido.

\section{Referências}

ABREU, Alzira Alves de. A modernização da imprensa (1970-2000). Rio de Janeiro: Jorge Zahar, 2002.

ADGHIRNI, Zélia. "Rotinas produtivas do jornalismo em Brasília". In MOILLAUD, Maurice e PORTO, Sérgio Dayrell. (orgs.) O jornal: da forma ao sentido. Brasília: editora UNB, 2002.

ALBUQUERQUE, Afonso e FORTES, Rafael. "O jornalismo e a obrigatoriedade do diploma: negociando as fronteiras da comunidade jornalística no Brasil". Comunicação e Sociedade, 9-10: 169-188, 2006.

BARBOSA, Marialva. História cultural da imprensa: 1900 - 2000. Rio de Janeiro: Mauad, 2007

BOHÈRE,G. Profissão: jornalista: um estudo dos jornalistas como trabalhadores. São Paulo: Ltr; Brasília: OIT, 1994.

FIDALGO, Joaquim. O jornalista em construção. Porto: Porto Editora, 2009.

KUNCZIK, Michael. Conceitos de jornalismo. São Paulo: Edusp, 2002

LESTER, Marlyn e MOLOTCH, Harvey. "As notícias como procedimento intencional: acerca do uso estratégico de acontecimentos de rotina, acidentes e escândalos." In: TRAQUINA, Nelson (org) Jornalismo: questões, teoria e "estórias". Lisboa: Vega, 1993.

MARCONDES FILHO, Ciro. Comunicação e jornalismo: a saga dos cães perdidos. São Paulo: Hackers, 2000.

MOILLAUD, Maurice e PORTO, Sérgio Dayrell. (orgs.) O jornal: da forma ao sentido. Brasília: editora UNB, 2002.

MOREL, Marco e BARROS, Mariana Monteiro. Palavra, imagem e poder: o surgimento da imprensa no Brasil do século XIX. Rio de Janeiro: Vozes, 2003.

RIBEIRO, Ana Paula Goulart. Imprensa e história no Rio de Janeiro dos anos 50. Tese de doutorado, Rio de Janeiro, ECO/UFRJ, set. 2000

SAPERAS, Enric. Os efeitos cognitivos da comunicação de massa. Porto: Asa, 2000 
SILVA, Carlos Eduardo Lins da. Mil dias: seis mil dias depois. São Paulo: Publifolha, 2005.

SILVA, Rafael Souza. Controle remoto de papel: o efeito zapping no jornalismo. São Paulo: Annablume; Fapesp, 2007.

SODRÉ, Nelson Werneck. História da imprensa no Brasil. Rio de Janeiro: Graal, 1977.

TRAQUINA, Nelson. O estudo do jornalismo no século XX. São Leopoldo: Unisinos, 2001.

Recebido em 10 de setembro de 2009

Aprovado em 29 de setembro de 2009 